\title{
AN INVESTIGATION INTO THE USE OF “HYBRID" ADJUSTMENT TECHNIQUES IN THE APPLICATION OF THE SALES COMPARISON METHOD IN RESIDENTIAL VALUATION
}

\author{
Ephraim K. Munshifwa \\ School of the Built Environment \\ Copperbelt University, Zambia \\ e-mail:ephraim.munshifwa@cbu.ac.zm
}

\begin{abstract}
The sales comparison is the most common and universally accepted method in valuation. Although the theoretical entry point of the method is the same across most continents, its application in practice is varied and often determined by local circumstances. This often necessitates the modification of the method. For instance, while Zambian valuation practice uses this method in residential valuation, its application goes beyond the basic valuation model, incorporating a less known technique called the "reduced floor area (RFA)" technique. The RFA technique is a form of relative importance (weight) concept which assesses ancillary buildings on site relative to the main use; for residential properties this is the main house on site. Despite its obscurity in valuation literature, practitioners find its use acceptable within the dictates of local circumstances. Nonetheless, the lack of documentation means knowledge on the technique is transmitted verbally from senior valuers to graduates, and its application is not consistent across the profession, contributing to variances in the assessed values. This necessitates detailed scrutiny of the technique. Data for the study was collected from the Valuation Surveyors Registration Board (VSRB), a statutory body responsible for licensing valuers and regulating valuation practice. This is the first time the RFA technique is being discussed in a scholarly article.
\end{abstract}

Keywords: sales comparison, reduced floor area technique, real estate, adjustment techniques, Zambia.

JEL Classification: K11, Q51, R32.

Citation: Munshifwa, E. K. (2021). An investigation into the use of "hybrid" adjustment techniques in the application of the sales comparison method in residential valuation. Real Estate Management and Valuation, 29(1), 1-11.

DOI: https://doi.org/10.2478/remav-2021-0001

\section{Introduction and background}

The sales comparison is the most commonly used method in real estate valuation. This method, also known as the "comparable transactions method" (International Valuation Standards Council [IVSC] 2017, p.31) assesses value by comparing the property being valued to similar properties for which sales or transaction prices are available (Pagourtzi, et al., 2003; Machmin, 2008; Lusht, 2012; Appraisal Institute, 2013; Whipple,2013; IVSC, 2017). Its application and accuracy is largely dependent on local circumstances and the level of development of the real estate market, with the valuers' role being interpretation and application. In other words, valuers work as a proxy for the market, interpreting information on both sides (for buyers and sellers) when fixing a price; hence the assertion that "value" is a proxy for "price". 


\section{S sciendo}

The real estate market, within which valuers operate, is however laden with challenges and often classified as opaque and illiquid (Holtermans, 2016), meaning that the form the application of a method takes in practice is largely dependent on local circumstances and encountered challenges. So how do valuers overcome challenges imposed by local settings in which they operate? In practice, valuers devise "hybrid" techniques to arrive at the end result - the assessment of value. For instance, while the basic application of the sales comparison method is by making adjustments directly on sale prices, valuers in the global South make a number of modifications to its application. This paper examined the use of a technique commonly known as the "Reduced Floor Area" (RFA) technique, as an addition to the basic sales comparison model.

The aim of this paper was to explore alternatives undertaken by valuers in developing real estate markets when faced with challenges in the application of the sales comparison method in residential valuation practice. In a world of Automated Valuation Models (AVMs) and changing dynamics of real estate markets, the challenges of applying basic valuation methods in developing markets are sometimes forgotten. This study thus investigates the application of a hybrid technique in the sales comparison method in Zambian valuation practice. The RFA technique works on the principle of summation of reduced areas of all buildings on site. This requires the weighting or adjustment in importance of each improvement on site in relation to the main use on site. The total RFA is then multiplied by the analyzed market prices per square meter to obtain the market value of the property. An actual valuation of a residential property in Riverside, Kitwe is presented in Table 2 for more details.

Two interrelated questions guided this study: firstly, what is the theoretical basis of the sales comparison method? Secondly, what challenges do valuers face in its application in developing real estate markets and how do they overcome them?

This article is arranged as follows. After this introductory section, Section 2 reviews theoretical and empirical literature on the application of the sales comparison method. Section 3 discusses the methodology used in this study, while Section 4 presents empirical findings. Section 5 is a discussion on findings, while section 6 concludes the paper with a recommendation for valuation practice in Zambia.

\section{Literature review: application of sales comparison method in real estate markets}

The direct sales comparison is the simplest and most direct method used in real estate valuation. It is based on the following model:

$$
M V=S_{\mathrm{c}}+A D J_{\mathrm{c}}
$$

Where $M V$ is the estimated market value, $S_{c}$ is the sales price of a comparable property and $A D J_{c}$ is the adjustment (positive or negative) to the sale price of the comparable property (Appraisal Foundation, 2014). Based on the principle of market substitution, the method arrives at an estimate of market value by comparing the property being valued with prices achieved for similar properties, while making adjustments for any differences between the sales evidence and the property being valued (Lusht, 2012; Shapiro, et al., 2013). In order to adjust for these differences, a number of standard techniques are used by valuers, which include summative percentage, dollar percentage, add/subtract percentage, proper base adjustment, review and intuition and paired sales regression analysis (Lusht, 2012; Shapiro, et al., 2013; Whipple, 2013). Up to this point, the basic theoretical grounding is acceptable to most scholars and practitioners around the world.

Literature, however, abounds on challenges in valuation, particularly when using the sales comparison method. These studies cover a number of issues, such as valuation accuracy (Aliyu, et al., 2018), uncertainty in valuation (French \& Gabrielli, 2004; Kucharska-Stasiak, 2013), information asymmetry (Garmaise \& Moskowitz, 2004; Firoozi,et al., 2006), valuation variances (Munshifwa, et al., 2016) and others. Thus, the reality is that, in practice, modifications are made to this basic model by practitioners as dictated by the type of property being valued, differences in the volume of market information available, technological advancements, increased client awareness, demands for more accuracy in the assessed values and generally changed dynamics in real estate markets (AddaeDapaah \& Ho, 1996; Aluko, et al., 2004; Appraisal Foundation, 2014; Bogin \& Shui, 2020). The Appraisal Foundation (2014) also shows that sales comparison is the underpinning approach in AVMs, through the direct market model or comparable sales models. 
Literature further points to the shortcomings of the basic sales comparison model, thus advocating for further advancements in its application. Bogin and Shui (2020), for instance, argued that property appraisals tend to be biased upwards. This upward biasness is more pronounced in rural areas where there is fewer sales evidence and houses are characterized by greater heterogeneity (Bogin\&Shui,2020); a comparable situation to what is found in most real estate markets in the global South. Thus, the study advocated for automated property value estimation using machine learning algorithms. Amidu, Aluko (2007) attributed this biasness in valuations to clients' influence. This was broken down into three factors seen as being responsible for this influence, namely: the integrity of the valuer (or firm), client size, and the importance of the valuation outcome to the client. Cupal (2014) also argued that adjusting for difference or heterogeneity is one of the key tasks for valuers, and a necessity for accurate assessments.

The type of property also has a bearing on the choice of the method and its application. For instance, Addae-Dapaah and Ho (1996) argued that the direct sales comparison method has methodological constraints when used for office valuations. In order to improve its effectiveness, the study suggested incorporation of appropriate details on the conditions of a sale and the terms of financing in the associated adjustment process. In essence, the study advocated for a taking another look at the adjustment techniques used in Singapore when using the direct sales comparison for office valuations. This equally applies to residential valuation. However, the study acknowledged that the direct sales comparison is the most popular and universally used method in real estate valuations (Addae-Dapaah\& Ho 1996).

Bello and Bello (2009) also argued that the direct sales comparison method is not appropriate when valuing properties in close proximity to waste dump sites, despite being a frequently used technique. The study then advocated for the use of more modern techniques, such as Contingent Valuation Analysis (CVA), Option Pricing Models and Hedonic Pricing Models. It is, however, important to note that most modern techniques, such as Hedonic Pricing Model (HPM), do not necessarily depart from the basic principle of the direct sales comparison model discussed earlier, but make modifications to suit the type of property being valued. For instance, HPM relies on comparable transaction prices to adjust for the effects of environmental factors (such as air, water and noise pollution) on the valuation outcome; the sales comparison model is, therefore, at its base. Malieneet al. (2010) refers to the comparison method as one of the traditional and classical methods. Applied directly or indirectly, it forms the base for statistical and multiple criteria analyses, including AVMs.

For countries such as Zambia, where obtaining transaction data is a major challenge, the application of the direct sales comparison model poses its own challenges. For instance, Makurira and Juru (2019) argued that most Zimbabwean valuers depend on experience and their wide professional networks to accomplish valuation assignments. In such settings, the main adjustment technique available to valuers is what Whipple (2013) calls "review and intuition". Makurira and Juru (2019) thus advocated for the establishment of a central database to overcome data challenges

An additional reason behind the impreciseness in valuation outcomes is the imperfection of the market itself (Aluko, et al., 2004). This makes uncertainty endemic in valuation assignments (Bywater,2011; IVSC 2013). This uncertainty is related to the quality and volume of the market data available, firms' involvement in similar valuation assignments and reliance on unverified information given by clients/third party advisers (Bywater, 2011). A number of factors were identified as major sources of uncertainty in valuation, namely, economic, financial and political, legal and regulatory, physical, occupational, leasing and valuation (Bywater, 2011). Differences in these factors will also have implications on how the sales comparison model is applied in different settings. The reviewed literature helped to show that, although the basic direct sales comparison model is commonly and universally accepted, its application in practice is largely dependent on a number of factors including the type of property being valued, differences in the volume of market information available, technological advancements, increased client awareness, demand for more accuracy in assessed values and, generally, changes in the dynamics of real estate markets. Due to the effect of these factors, the response from valuers has involved modifications to the basic model and calls for the use of more modern and advanced methods, such as artificial neural networks (ANNs), hedonic pricing, fuzzy logic, spatial analysis, autoregressive integrated moving averages (ARIMA) and multiple criteria methods (Maliene, et al., 2010). Interestingly, most of these methods depend on transaction data and some form of comparison to arrive at an estimate of value. 
Zambia, like a number of its neighboring countries, faces similar challenges in the application of the direct sales comparison model, which has necessitated modifications in practice. For instance, Zambia has adopted the separation of values between the land and improvements, particularly in the assessment of property tax. This is clear for countries such as Botswana, Namibia, Lesotho and Swaziland (Franzsen, 2002). Thus, a similar procedure, including the use of reduction factors, is used for the assessment of market values in most Southern African countries, with concomitant challenges. The introduction of factor reduction beyond the analyzed market rate per square meter contributes to variances in the final value outcome.

Studies in the sub region (see Chirisa \& Juru, 2019; Marongwe, et al., 2011; Munshifwa, et al., 2016) also support the challenges of applying the basic direct sales comparison method. For instance, Marongwe, et al., (2011) noted that the Zimbabwean real estate sector is characterized by unavailability of information, such as volumes of trade, value of transactions and trends in property transactions, which should be publicly available. The absence of such information affects the functioning of the real estate market, thus impacting the application of the sales comparison method in valuation practice (Marongwe, et al., 2011). This has contributed to wide variances in the assessed values. In this regard, Chirisa and Juru (2019) noted that, although internationally variances of 5\% $10 \%$ are accepted as normal, these can be as much as seven-fold in the Zimbabwean case. Similarly wide variations, ranging between $10 \%$ and $25 \%$, were noted in the Zambian rating valuation practice by Munshifwa et al. (2016). In order to mitigate the problem of variances emanating beyond the analyzed and adjusted market price per square meter in the assessment process, Zimbabwean valuers collectively agreed to apply standard reduction factors as shown in Table 1 below. This is in an effort to minimize variances beyond the use of standard adjustment techniques when applying the sales comparison method.

Table 1

Reduction factors used in Zimbabwean valuation practice

\begin{tabular}{ll}
\hline Improvements & Reduction Factor \\
\hline Main house & 1.00 \\
\hline Verandah (enclosed under main roof) & 0.80 \\
\hline Verandah (Open) under main roof & 0.60 \\
\hline Porch & 0.30 \\
\hline Pergola, no surfaced floor & 0.07 \\
\hline Pergola, hard surfaced floor & 017 \\
\hline Garage with doors & 0.40 \\
\hline Garage without doors & 0.40 \\
\hline Carport, no surfaced area & 0.15 \\
\hline Carport with hard surface floor & 0.20 \\
\hline Living Quarters, self-contained & 0.40 \\
\hline Living Quarters, compound type & 0.30 \\
\hline Pool decks and Patios & 0.10 \\
\hline Sheds/stores (detached) & 0.20 \\
\hline Sheds, store (detached) hard surface & 0.35 \\
\hline Pavilion hard floor surface/roof & 0.20 \\
\hline
\end{tabular}

Source: Real Estate Institute of Zimbabwe (n.d), unpublished circular.

It is important, at this point, to iterate the fact that the application of the sales comparison method is challenged by different local realities forcing valuers to devise hybrid techniques (as additions to standard adjustment techniques) which rely more on individual experience and intuition (Whipple, 2013). However, this study asserts that valuation practice has, over many years, produced knowledge through practice, which requires critical examination. This paper uses the example of the reduced floor area technique in Zambian practice to demonstrate how collective knowledge is still useful in realities of the global South.

\section{Data and methods}

This study was based on data collected from documents submitted and stored by the Valuation Surveyors Registration Board (VSRB), a statutory body constituted under the Valuation Surveyors Act 
Cap 207 to license practicing valuers and regulate the valuation profession. These documents included Valuation Reports, Log Books, Diaries, Valuation Reports and the Critical Analysis Reports, submitted by candidates for the Assessment of Professional Competence (APC). All documents are countersigned by supervisors before submission.

A total of 127 reports were scrutinized for this study, out of which 80 were residential valuations. The process of data collection focused on assessed market values, calculated floor areas, reduction factors and reduced floor areas. Data was first collected and stored in various Excel sheets, next extracting relevant information for the creation of the SPSS database. Where reduction factors were missing, market prices $/ \mathrm{m}^{2}$ were used to calculate Reduction Factors as shown in Table 2. SPSS was used for analysis. The one Sample $t$-test was used to examine whether information on the choice of reduction factors can be related to firms within which valuers work. In other words is there a difference in the adoption of reduction rates between/within firms? Because Zimbabwe has already established reduction factors, unlike Botswana and Namibia in the sub region, this study further used the one-sample $t$-test to analyze if there were significant differences between reduction factors used in Zambia and Zimbabwe.

\section{Empirical findings}

As a starting point for this section, the paper sought to establish the most commonly used method in the valuation of residential properties, and thereafter examined the application of the Reduced Floor Area technique.

\subsection{Application of the sales comparison method}

The study confirmed that the direct sales comparison was the main valuation method for residential real estate in Zambia; all 80 residential valuations used this method. However, the study also noted that its application is slightly different from that stated in theoretical literature. For instance, while the main application in literature is directly on sale price, adjustments in Zambian practice are mainly on the analyzed market price per square meter. At this level, various adjustment techniques, such as the summative percentage, dollar percentage, add/subtract percentage, proper base adjustment, review and intuition and pair sales regression analysis (Lusht, 2012; Shapiro, et al., 2013) are applicable. However, in Zambian practice, market value is assessed as the summation of improvement and land values; similar to what Franzsen (2002) noted for Botswana, Namibia, Lesotho, and Swaziland in the assessment of property tax. Practice thus uses a procedure similar to the summation method within the cost approach (IVSC 2017), which separates values of the constituent parts of an asset.

In Zambia, this "split" is a result of government legislation with a long history. For instance, the Land Act of 1975, which "abolished" value on land, went further to recognize only value of "unexhausted improvements" - defined as any building resulting from capital expenditure or application of labor (GRZ 1975). This separation of values was replicated in other Acts, such as the Rating Act of 1979, which provided that entries in the Valuation Roll should be divided into improvement value and land value. The result is that adjustments in Zambian valuation practice are made on the analyzed and adjusted market price per square meter of the comparable. After following the standard valuation process up to this point, the Reduced Floor Area (RFA) technique is then introduced in the assessment.

A further effect of the 1975 Land Act was that it introduced distortions in the real estate market through some form of price control. This meant that, before any transfer of interest in property, the buyer needed to obtain consent from the State. For instance, Musole (2007, p. 267) argued that regulations in the Land Act of 1975 presented a "real formidable problem that impacted negatively on valuation accuracy" through alteration of property rights and distortion in pricing. Furthermore, due to what was seen as speculative transactions on land, the government banned all forms of facilitation of land sales and blamed real estate agents for the "vice" (Kaunda,1975). In addition, the Land Act prohibited the sale or transfer of any undeveloped land. This resulted in the creation of an opaque real estate market from 1975 to 1991, where the availability and quality of information, as an input in the valuation process, became a serious challenge for valuers. Despite the replacement of the 1975 Land Act with a 1995 revision, which recognizes the value of undeveloped land (GRZ 1995), and the Estate Agents Act of 2000, which legalizes estate agency practice (GRZ 2000), the Zambian market still suffers from a number of shortcomings, impacting the application of the sale comparison method . 


\subsection{Application of the Reduced Floor Area technique}

Unlike the standard adjustment techniques, the RFA is not sufficiently documented in literature, and yet, is used as an extension of these techniques in Zambian valuation practice. In other words, after the market rate per square meter is derived from sales information, its application to ancillary buildings on the same site has to be further adjusted. This study, therefore, both documents the RFA as well as providing a basis for its critique and interrogation. As noted earlier, the RFA technique is partly a result of restrictions emanating from the Land Act of 1975 due to its effect on the flow of information. The technique works on the principle of summation of reduced areas of all buildings on site. For instance, if the permitted use on site is residential, the main building on site is then the dwelling house and living spaces in that house; therefore any other improvements on this site are ancillary to the main use. Table 2 below shows an actual valuation of a residential property in Riverside, Kitwe using this technique. In this example, each improvement is reduced by a reduction factor (RF) which is a proportion in relation to 1, the factor assigned to the main use on site. The summation of the reduced areas (i.e. RF multiplied by floor areas) gives it the name Reduced Floor Area technique.

Most residential valuations follow four basic steps (Machmin, 2008): (i) selecting sales comparable information, (ii) extracting, confirming and analyzing comparable sale prices, (iii) adjusting sales prices for noted differences and, (iv) formulating an opinion of market value for the subject property. A typical application of these four steps in the Zambian valuation practice is shown in Table 2 with a reported final market value of $\mathrm{K} 1,991,000.00$. A scrutiny of the "market rate $/ \mathrm{m}^{21}$ column reveals that $\mathrm{K} 4,600.00$ is the analyzed and adjusted rate (Steps 2 and 3) applicable to this property. However, the application of $\mathrm{K} 4,600.00$ pertains only to the main house, therefore another step has to be used to "adjust" the main rate such that it can be applied to other improvements on the same site. This requires that lower rates of $K 1,840.00$ per square meter for the servants' quarter, $K 2,760.00$ for the enclosed veranda and K 3,680.00 for the guest wing/garage be used. The quantum at which the rate of $\mathrm{K} 4,600.00$ is reduced when applied to other improvements is known as the "Reduction Factor" and is shown in the "RF" column in Table 2. This paper asserts that this has come up through practice, with little or no scholarly documentation; however its use is widespread, hence the need to examine its efficacy.

Theoretically, the RFA could be said to be using some form of relative importance (weight) concept, similar to the procedure used for explanatory variables in regression analysis. Thus, the value of all other buildings on site is determined in relation to the value of the main house through a reduction process on the analyzed market value per square meter.

Table 2

Valuation of residential property on Kaminda Drive, Kitwe

\begin{tabular}{lllll}
\hline \multicolumn{1}{c}{ Description } & FloorArea $\left(\mathbf{m}^{2}\right)$ & \multicolumn{1}{c}{ RF } & Market Rate/m2 & \multicolumn{1}{c}{ Value } \\
\hline Main house & 276.45 & 1.00 & $\mathrm{~K} 4,600.00$ & $\mathrm{~K} 1,271,670.00$ \\
\hline Enclosed veranda & 8.89 & 0.60 & $\mathrm{~K} 2,760.00$ & $\mathrm{~K} \mathrm{24,536.40}$ \\
\hline Guestwing/Garage & 86.17 & 0.80 & $\mathrm{~K} 3,680.00$ & $\mathrm{~K} 317,105.60$ \\
\hline Servants' quarters & 13.23 & 0.40 & $\mathrm{~K} 1,840.00$ & $\mathrm{~K} \mathrm{24,343.20}$ \\
\hline Land (in sqm) & 1536.00 & & & $\mathrm{~K} 276,480.00$ \\
\hline Boundary Wall Fence & & & & $\mathrm{K} 32,000.00$ \\
\hline Surrounding Paving & & & $\mathrm{K} 45,000.00$ \\
\hline MARKET VALUE & & & $\mathrm{K} 1,991,135.20$ \\
\hline
\end{tabular}

Source: Extracted from Critical Analysis Report submitted to VSRB by APC candidate.

Two clear observations need to be emphasized from the valuation assessment in Table 2:

1) The technique used a form of the summation method, where values of individual improvements are added to obtain the final market value. Thus, land and improvements are valued separately. This is different from the way it is applied in developed markets, where adjustment is done directly at the sales price level and the end result is the final value estimate sought. 
2) While standard adjustments techniques are applicable when deriving the market rate per square (in this instance, $\mathrm{K} 4,600.00$ ), this is further adjusted downwards when applied to any other improvements on site. This reduction is dependent on the reduction factor adopted for each improvement on site by the valuer. This constitutes a modification to the direct sales comparison model as discussed in Appraisal Foundation (2014).

The implication of these two findings is that valuers will, in practice, make modifications or additions to the basic sales comparison model to suit different realities or settings. However, as these modifications are made, it is vital that these are underpinned by a theoretical grounding in valuation literature, hence the need for their continuous interrogation.

\subsection{Descriptive statistics}

Despite many years of its application, the RFA technique is not applied uniformly amongst practicing valuers. The result is that, this too, contributes to variances in the final assessed market value, particularly in the global South with developing real estate markets. In practice, valuers use different reduction factors for similar improvements on site. In such cases, valuers depend more on their experience, which is argued to be inadequate in a science-based profession (Rowland, 1991; Whipple, 2013). It is for this reason that the actual reduction factors used by valuers needed to be examined.

Out of the 80 residential valuations examined, $50(62.5 \%)$ were used for this examination (see Table 3). The study found discrepancies in the adoption of reduction factors in some cases. For instance, although most valuers used 0.30 for verandas, further analysis revealed that, in many cases, there was a difference between what most valuers used and the mean. For instance, this was observed for the front veranda (Mode $=0.30$; mean $=0.31 ; \mathrm{SD}=0.05390)$, carport $($ Mode $=0.50$; mean $=0.33 ; \mathrm{SD}$ $=0.08829)$, storage room $($ Mode $=0.40 ;$ mean $=0.31 ; \mathrm{SD}=0.10951)$ and garage $($ Mode: 0.40 ; Mean $=$ 0.42 ; $\mathrm{SD}=0.05991$. This has implications on the final value outcome and contributes to variances. These results confirm the inconsistencies in the application of reduction factors due to differences in the experience of valuers and available information. Admittedly, while valuers may not be forced to adopt the same reduction factors for all the improvements on site, such adoption should not lead to wide variances in the assessed value. Valuation outcomes should fall in a range which is statistically acceptable.

Table 3

Descriptive statistics

\begin{tabular}{lcccccccc}
\hline & $\mathrm{N}$ & Range & Mini & Maxi & Mean & $\begin{array}{l}\text { Std. } \\
\text { Deviation }\end{array}$ & Variance & Mode \\
\hline MAIN HOUSE & 50 & 0.00 & 1.00 & 1.00 & 1.00 & 0.00 & 0.00 & 1.00 \\
\hline $\begin{array}{l}\text { FRONT } \\
\text { VERANDA }\end{array}$ & 42 & 0.45 & 0.15 & 0.60 & 0.31 & 0.05 & 0.00 & 0.30 \\
\hline SERVANTS' QTRS & 28 & 0.41 & 0.33 & 0.74 & 0.50 & 0.11 & 0.01 & 0.50 \\
\hline REAR VERANDA & 15 & 0.05 & 0.30 & 0.35 & 0.31 & 0.02 & 0.00 & 0.30 \\
\hline CARPORT & 15 & 0.30 & 0.10 & 0.40 & 0.33 & 0.09 & 0.00 & 0.50 \\
\hline STORE ROOM & 14 & 0.35 & 0.15 & 0.50 & 0.31 & 0.11 & 0.01 & 0.40 \\
\hline GARAGE & 13 & 0.20 & 0.40 & 0.60 & 0.42 & 0.06 & 0.00 & 0.40 \\
\hline GUARD HOUSE & 6 & 0.60 & 0.20 & 0.80 & 0.41 & 0.22 & 0.05 & 0.20 \\
\hline SECOND HOUSE & 4 & 0.00 & 1.00 & 1.00 & 1.00 & 0.00 & 0.00 & 1.00 \\
\hline PUMP HOUSE & 4 & 0.41 & 0.10 & 0.51 & 0.29 & 0.18 & 0.03 & 0.10 \\
\hline WORKERS' QTRS & 3 & 0.10 & 0.40 & 0.50 & 0.47 & 0.06 & 0.00 & 0.50 \\
\hline DOG KENNEL & 3 & 0.20 & 0.10 & 0.30 & 0.21 & 0.10 & 0.01 & 0.10 \\
\hline BALCONY & 2 & 0.02 & 0.28 & 0.30 & 0.29 & 0.01 & 0.00 & \\
\hline
\end{tabular}

Source: Author.

In practice, the application of the RFA by individual valuers contributes to differences in the assessed values. In order to prove this assertion, the analyzed maximum and minimum floor areas from Table 3 were applied to details of an actual valuation presented earlier in Table 2. Ancillary space which needed reduction included the enclosed front veranda, guest wing/garage and servants' quarter. Results presented in Table 4 show that, using the MiniRF and MaxiRF, the total reduced floor 
areas were $311.18 \mathrm{~m}^{2}$ and $352.40 \mathrm{~m}^{2}$, respectively. This represents a difference of $13 \%$. Applying the same rate of $K 4,600$ as in the actual valuation plus values for the land, boundary wall fence and paving resulted in market values of $\mathrm{K} 1,784,901.56$ (minimum) and $\mathrm{K} 1,974,521.38$ (maximum), with the reported value of $\mathrm{K} 1,991,000$ falling in-between. The difference between the maximum and minimum values was $13 \%$. In some cases, the difference in the reduced areas of individual buildings was as high as $300 \%$ (see Table 4 ).

Table 4

Difference in application of RFs and value outcomes

\begin{tabular}{|c|c|c|c|c|c|c|}
\hline & Area $\left(\mathrm{m}^{2}\right)$ & MiniRF & MaxiRF & MiniRFA & MaxiRFA & Diff \\
\hline MAIN HOUSE & 276.45 & 1 & 1 & 276.45 & 276.45 & $0 \%$ \\
\hline ENCLOSED VERANDA & 8.89 & 0.15 & 0.6 & 1.33 & 5.33 & $300 \%$ \\
\hline $\begin{array}{l}\text { GUEST } \\
\text { WING/GARAGE }\end{array}$ & 89.17 & 0.33 & 0.74 & 29.42 & 65.98 & $124 \%$ \\
\hline SERVANTS' QUARTER & 13.23 & 0.3 & 0.35 & 3.96 & 4.63 & $17 \%$ \\
\hline TOTAL RFA & & & & 311.18 & 352.40 & $13 \%$ \\
\hline Market price/m2 & & & & $4,600.00$ & $4,600.00$ & \\
\hline Value of improvements & & & & K 1,431,421.56 & K 1,621,041.38 & $13 \%$ \\
\hline add Land value & & & & $276,480.00$ & $276,480.00$ & \\
\hline addBoundarywallfence & & & & $32,000.00$ & 32,000 & \\
\hline addPaving & & & & $45,000.00$ & $45,000.00$ & \\
\hline MARKET VALUE & & & & K 1,784,901.56 & K 1,974,521.38 & $13 \%$ \\
\hline
\end{tabular}

Source: Author.

The study further questioned whether the choice of reduction factors could be ascribed to the subset of information in valuation firms. In other words, is there is common understanding for all firms as to what reduction factors should be applied on ancillary buildings? ANOVA results in Table 5 revealed mixed results. For instance, results showed that, besides the rear veranda $(F=3.467$; $p=0.050)$ and servants' quarters $(F=3.034 ; p=0.024)$, all other variables showed no relationship between valuation firms and the use of reduction factors. That is to say, evidence does not support the hypothesis that valuers are cultured within firms on the adoption of reduction factors, leaving the choice up to individuals.

Table 5

ANOVA Test of Valuation firms and use of reduction factors

\begin{tabular}{lllllllc}
\hline ANOVA Tablea,b,c,d,e,f & & & & & & \\
\hline & & & $\begin{array}{l}\text { Sum of } \\
\text { Squares }\end{array}$ & df & $\begin{array}{l}\text { MeanSq } \\
\text { uare }\end{array}$ & F & Sig. \\
\hline $\begin{array}{l}\text { FRONT VERANDA } \\
\text { VALUATION FIRM }\end{array}$ & $* \begin{array}{l}\text { BetweenGro } \\
\text { ups }\end{array}$ & (Combined) & 0.01 & 9 & 0.00 & 0.20 & 0.99 \\
\hline $\begin{array}{l}\text { REAR VERANDA } \\
\text { VALUATION FIRM }\end{array}$ & $* \begin{array}{l}\text { BetweenGro } \\
\text { ups }\end{array}$ & (Combined) & 0.00 & 4 & 0.00 & 3.47 & 0.05 \\
\hline $\begin{array}{l}\text { SERVANTS' QUARTERS * } \\
\text { VALUATION FIRM }\end{array}$ & $\begin{array}{l}\text { BetweenGro } \\
\text { ups }\end{array}$ & (Combined) & 0.16 & 7 & 0.02 & 3.03 & 0.02 \\
\hline $\begin{array}{l}\text { GARAGE * VALUATION } \\
\text { FIRM }\end{array}$ & $\begin{array}{l}\text { BetweenGro } \\
\text { ups }\end{array}$ & (Combined) & 0.00 & 3 & 0.00 & 0.34 & 0.80 \\
\hline $\begin{array}{l}\text { CARPORT * VALUATION } \\
\text { FIRM }\end{array}$ & $\begin{array}{l}\text { BetweenGro } \\
\text { ups }\end{array}$ & (Combined) & 0.02 & 6 & 0.00 & 0.38 & 0.87 \\
\hline $\begin{array}{l}\text { GUARD HOUSE } \\
\text { VALUATION FIRM }\end{array}$ & $\begin{array}{l}\text { BetweenGro } \\
\text { ups }\end{array}$ & (Combined) & 0.12 & 4 & 0.03 & 0.26 & 0.88 \\
\hline $\begin{array}{l}\text { STORE ROOM } \\
\text { VALUATION FIRM }\end{array}$ & $\begin{array}{l}\text { BetweenGro } \\
\text { ups }\end{array}$ & (Combined) & 0.04 & 4 & 0.01 & 0.67 & 0.63 \\
\hline
\end{tabular}


a. No variance within groups - statistics for MAIN HOUSE * VALUATION FIRM cannot be computed. b. No variance within groups - statistics for SECOND HOUSE * VALUATION FIRM cannot be computed.

c. Too few cases - statistics for BALCONY * VALUATION FIRM cannot be computed.

d. Too few cases - statistics for WORKERS' QUARTERS * VALUATION FIRM cannot be computed.

e. Too few cases - statistics for PUMP HOUSE * VALUATION FIRM cannot be computed.

f. With fewer than three groups, linearity measures for DOG KENNEL * VALUATION FIRM cannot be computed.

Source: Author.

\subsection{Regional comparison on the application of reduction factors}

As earlier noted, the use of the reduced floor area technique is common within the Southern African sub-region. Hence, this paper hypothesized that the relationship between the main dwelling house and other ancillary buildings should not be different, whether it be in Botswana, Zambia, Zimbabwe or Namibia, if the logic of the technique is the same. The study therefore tested the hypothesis that there is no significant difference between reduction factors as used in valuation practice in Zambia and Zimbabwe. The one-sample $t$-test was used for this purpose. Results in Table 6 below revealed that, in some cases, there were differences in the application. For instance, there were significant differences in the application of reduction factors on the front veranda $(t=-35.127 ; p=0.000)$, rear veranda $(t=-61.107 ; p=0.000)$, servants' quarters $(t=4.281 ; p=0.000)$ and storage room $(t=3.782$; $p=0.002)$. These results indicate that, since $p<0.05$, the study rejects the null hypothesis that there is no difference. This again points to the need for further discussion on the application of the technique, not just within the country but also across the sub-region.

Table 6

A sample t-test of reduction factors in Zambia and Zimbabwe

\begin{tabular}{|c|c|c|c|c|c|c|c|c|}
\hline & \multirow{2}{*}{$\begin{array}{l}\text { Zambian } \\
\text { mean }\end{array}$} & \multirow{2}{*}{$\begin{array}{c}\text { Test } \\
\text { value }\end{array}$} & \multirow[t]{2}{*}{$\mathrm{t}$} & \multirow{2}{*}{$\mathrm{df}$} & \multirow{2}{*}{$\begin{array}{l}\text { Sig. (2- } \\
\text { tailed) }\end{array}$} & \multirow{2}{*}{$\begin{array}{l}\text { Mean } \\
\text { Diff. }\end{array}$} & \multicolumn{2}{|c|}{$\begin{array}{c}95 \% \text { Confidence } \\
\text { Interval of the Diff. }\end{array}$} \\
\hline & & & & & & & Lower & Upper \\
\hline FRONT VERANDA & 0.31 & 0.60 & -35.12 & 41 & 0.00 & -0.29 & -0.31 & -0.28 \\
\hline REAR VERANDA & 0.31 & 0.60 & -61.10 & 14 & 0.00 & -0.29 & -0.30 & -0.28 \\
\hline SERVANTS' QTRS & 0.50 & 0.40 & 4.28 & 27 & 0.00 & 0.08 & 0.04 & 0.13 \\
\hline GARAGE & 0.42 & 0.40 & 1.38 & 12 & 0.19 & 0.02 & -0.01 & 0.06 \\
\hline CARPORT & 0.33 & 0.30 & 1.46 & 14 & 0.16 & 0.03 & -0.02 & 0.08 \\
\hline STORAGE ROOM & 0.31 & 0.20 & 3.78 & 13 & 0.00 & 0.11 & 0.05 & 0.17 \\
\hline
\end{tabular}

Source: Author.

\section{Discussion}

The entry point for this paper was that the direct sales comparison is the most common and universally accepted valuation model. However, its application is often challenged by varied local settings necessitating modification or adjustments in practice. The reduced floor area technique was cited as an example. The RFA is introduced after the use of standard techniques, such as the summative percentage, dollar percentage, add/subtract percentage, proper base adjustment, review and intuition, and pair sales regression analysis. Furthermore, as opposed to the standard adjustment of the sales price in the direct sales comparison, adjustments are made on the market price per square meter.

The RFA was explained as a form of relative importance (weight) concept which assesses ancillary buildings on site relative to the main use; for residential properties this is the main house. However, findings further revealed that the use of the RFA does not totally eliminate incidences of variances because of their differential application amongst practicing valuers. Using a number of ways, the paper proved that differential application of input data into the valuation equation, even at the level of calculating the reduced floor area, results in variances in the final assessed market values. For instance, the study used an actual valuation of a property in Riverside, Kitwe and descriptive statistics to show that the adoption of minimum and maximum reduction factors would result in a $13 \%$ 
difference in values. The paper recommends more detailed scrutiny of the application of these techniques by the Valuation Surveyors Registration Board (VSRB) and the Valuation Chapter of the Surveyors Institute of Zambia (SIZ).

\section{Conclusion}

This paper concludes that, while prima facie the application of the RFA technique maybe defendable, the mental and internal process of deriving the reduction factors of ancillary buildings is unclear. The internal logic of the reduction process therefore needs further interrogation. One question that may be asked is: are valuers clear as to why 0.50 is used for servants' quarters instead of 0.40 ? There is a need for more detailed examination of the internal workings of the logic, including its theoretical underpinning. Since the technique is a derivative from practice, this should involve professional valuers in a robust and open discussion on these reduction factors and reach a consensus on their application in a process contributing to minimizing valuation variances when using the sales comparison model.

\section{Reference}

Addae-Dapaah, K., \& Ho, D. (1996). The effectiveness of the direct sale comparison approach to office appraisal in Singapore, Australian Land Economics Review, 2(2), 35-43.

Aliyu, B. A., Sani, H., Usman, H., \& Muhammad, H. (2018). Ranking the Causative Factors of Mortgage Valuation Inaccuracy in Kaduna Metroplois. Real Estate Management and Valuation, 26(3), 71-81. https://doi.org/10.2478/remav-2018-0026

Aluko, B. T., Ajayl, C. A., \& Amidu, A. R. (2004). The estate surveyors and valuers and the magic number: A point estimate or a range of value? International Journal of Strategic Property Management, 8(3), 149-162. https:// doi.org/10.3846/1648715X.2004.9637514

Appraisal Foundation. (2014). APB Valuation advisory No 5 - Identifying comparable properties in Automated Valuation Models for mass appraisal. Appraisal Foundation.

Amidu, A. R., \& Aluko, B. T. (2007). Client influence on valuation: Perceptual analysis of the driving factors. International Journal of Strategic Property Management, 11(2), 77-89. https://doi.org/10.3846/1648715X.2007.9637562

Appraisal Institute. (2013). The Appraisal of Real Estate (14th ed.). Appraisal Institute.

Bello, V. A., \& Bello, M. O. (2009). Valuation of properties in close proximity to waste dumps sites: The Nigeria experience. International Journal of Strategic Property Management, 13(4), 309-317. https:// doi.org/10.3846/1648-715X.2009.13.309-317

Bogin, A. N., \& Shui, J. (2020). Appraisal Accuracy and Automated Valuation Models in Rural Areas. The Journal of Real Estate Finance and Economics, 60, 40-52. https://doi.org/10.1007/s11146-019$\underline{09712-0}$

Bywater, N. (2011). Reflecting uncertainty in valuations for investment purposes: A brief guide to users of valuations, June2011/VP/942RS. RICS.

Chirisa, I., \& Juru, M. (Eds.). (2019). Aspects of Real Estate Theory and Practice in Zimbabwe: An Exploratory Text. Langaa Research and Publishing, Mankon, Bamenda. https://doi.org/10.2307/j.ctvpb3vnj

Cupal, M. (2014). The comparative approach theory for real estate valuation. Procedia: Social and Behavioral Sciences, 109, 19-23. https://doi.org/10.1016/j.sbspro.2013.12.414

Firoozi F., Hollas D.R., Rutherfordr.C., \& Thomson T.A. (2006). Property assessments and information asymmetry in residential real estate. Journal of Real Estate Research, 28(3), 275-291.

Franzsen, R. C. D. 2002, Property assessment for rating purposes in Southern and East Africa: Present status and future prospects. Paper presented at the 8th Annual Conference of the Pacific Rim Real Estate Society, 21-23 January, Christchurch New Zealand.

French, N., \& Gabrielli, L. (2004). The uncertainty of valuation. Journal of Property Investment \& Finance, 22(6), 484-500. https://doi.org/10.1108/14635780410569470

Garmaise M.J., \& Moskowitz T.J. 2004. Confronting information asymmetries: Evidence from real estate markets. The Review of Financial Studies, 17(2), pp. 405-437.

Government Of The Republic Of Zambia. (1975). Land (Conversion of Titles) Act. Government Printers.

Government Of The Republic Of Zambia. (1995). Lands Act. Government Printers.

Government Of The Republic Of Zambia. (2000). Estate Agents Act. Government Printers. 
Holtermans, R. 2016. Information asymmetry and sustainability in real estate markets. Unpublished $\mathrm{PhD}$ thesis, Maastricht University School of Business and Economics, Maastricht, the Netherlands. International Valuation Standards Council. (2013). Valuation uncertainty. IVSC.

International Valuation Standards Council. (2017). International Valuation Standards 2017. IVSC.

Kaunda, D. K. (1975). The Watershed Speech. Government Printers.

Kucharska-Stasiak, E. (2013). Uncertainty of property valuation as a subject of academic research. Real Estate Management and Valuation, 21(4), 17-25. https://doi.org/10.2478/remav-2013-0033

Lusht, K. M. (2012). Real Estate Valuation: Principles and Applications. KML Publishing.

Machmin, D. (2008). The Valuation and Sale of Residential Property (3rd ed.). Routledge.

Makurira, R., \& Juru, M. (2019). Statutory valuation in Zimbabwe. In I. Chirisa \& M. Juru (Eds.), Aspects of Real Estate Theory and Practice in Zimbabwe: An Exploratory Text. Langaa RPCIG. https://doi.org/10.2307/j.ctvpb3vnj.10

Maliene V., Deveikis S., Kirsten L., \& Malys L. 2010 Commercial leisure property valuation: A comparison of the case studies in UK and Lithuania. International Journal of Strategic Property Management, 14(1), 35-48.

Marongwe, N., Mukoto, S., \& Chatiza, K. 2011. Governance of urban land markets in Zimbabwe. Scoping Study, Urban LandMark, available at: http://urbanlandmark.org/downloads/scoping_study_gov_ulm_zimbabwe.pdf $\quad$ (accessed 4 October 2019).

Munshifwa, E. K., Jain, N., Kaunda, B. S., Masiba, L., Lungu, J., Chunda-Mwango, N., Mushinge, A., \& Ngoma, W. (2016). Variances in rateable values in rating practice in Zambia: The role of mental models in value assessment. Pacific Rim Property Research Journal, 22(2), 181-201. https://doi.org/10.1080/14445921.2016.1225151

Musole, M. 2007. Land policy and the urban land market in Zambia: Property rights, transaction cost and institutional change. Unpublished PhD thesis, University of Glasgow, Glasgow, UK.

Pagourtzi, E., Assimakopoulos, V., Hatzichristos, T., \& French, N. (2003). Real estate appraisal: A review of valuation methods. Journal of Property Investment $\mathcal{E}$ Finance, 21(4), 383-401. https://doi.org/10.1108/14635780310483656

Real Estate Institute Of Zimbabwe (n.d). Reduction factors Unpublished circular, REIZ, Harare.

Rowland, P. (1991). The use of comparable sales for market valuation. The Valuer, (February), 332-367.

Shapiro, E., Mackmin, D., \& Sams, G. (2013). Modern Methods of Valuation (11th ed.). Routledge.

Whipple, R. T. M. 2013. Property Valuation and Analysis (2nd ed.). Lawbook Company, Pyrmont, N.S.W. 